\title{
Effects of a natural extract from Mangifera indica L, and its active compound, mangiferin, on energy state and lipid peroxidation of red blood cells
}

\author{
Janet Rodríguez ${ }^{\mathrm{b}, 1}$, Donato Di Pierro ${ }^{\mathrm{a}, 1}$, Magda Gioia ${ }^{\mathrm{a}}$, Susanna Monaco ${ }^{\mathrm{a}}$, René Delgado ${ }^{\mathrm{b}}$, \\ Massimiliano Coletta ${ }^{a}$, Stefano Marini ${ }^{\text {a,* }}$ \\ ${ }^{a}$ Department of Exp. Med. and Biochem. Sciences, University of Rome TorVergata, Via Montpellier 1, 00133 Rome, Italy \\ ${ }^{\mathrm{b}}$ Department of Biomedical Research, Center of Pharmaceutical Chemistry, 200 y 21, Atabey Playa, P.O. Box 16042, Havana, Cuba
}

Received 19 September 2005; received in revised form 11 April 2006; accepted 18 April 2006

Available online 4 May 2006

\begin{abstract}
Following oxidative stress, modifications of several biologically important macromolecules have been demonstrated. In this study we investigated the effect of a natural extract from Mangifera indica L (Vimang), its main ingredient mangiferin and epigallocatechin gallate (EGCG) on energy metabolism, energy state and malondialdehyde (MDA) production in a red blood cell system. Analysis of MDA, high energy phosphates and ascorbate was carried out by high performance liquid chromatography (HPLC). Under the experimental conditions, concentrations of MDA and ATP catabolites were affected in a dose-dependent way by $\mathrm{H}_{2} \mathrm{O}_{2}$. Incubation with Vimang (0.1, 1, 10, 50 and $100 \mu \mathrm{g} / \mathrm{mL})$, mangiferin $(1,10,100 \mu \mathrm{g} / \mathrm{mL})$ and EGCG $(0.01,0.1,1,10 \mu \mathrm{M})$ significantly enhances erythrocyte resistance to $\mathrm{H}_{2} \mathrm{O}_{2}$-induced reactive oxygen species production. In particular, we demonstrate the protective activity of these compounds on ATP, GTP and total nucleotides (NT) depletion after $\mathrm{H}_{2} \mathrm{O}_{2}$-induced damage and a reduction of NAD and ADP, which both increase because of the energy consumption following $\mathrm{H}_{2} \mathrm{O}_{2}$ addition. Energy charge potential, decreased in $\mathrm{H}_{2} \mathrm{O}_{2}$-treated erythrocytes, was also restored in a dosedependent way by these substances. Their protective effects might be related to the strong free radical scavenging ability described for polyphenols.

(C) 2006 Elsevier B.V. All rights reserved.
\end{abstract}

Keywords: Antioxidant; EGCG; Mangifera indica L; Mangiferin; Erythrocyte

\section{Introduction}

During electron transfer there is a production of free radicals, reactive oxygen species (ROS) and highly reactive oxygencontaining radicals by a wide range of different phenomena (e.g., oxidative metabolism of mitochondria, activation of inflammatory cells, hyperoxia, ischemia/reperfusion, the arachidonic acid cascade, cytochrome P450-mediated reactions and exposure to chemicals or physical agents, such as gamma rays) [1]. The first exhaustive experiments performed in human erythrocytes showed the ability of ROS to also induce lipid

\footnotetext{
* Corresponding author. Tel.: +39 0672596354; fax: +390672596353

E-mail address: stefano.marini@uniroma2.it (S. Marini).

${ }^{1}$ Both authors equally contributed to the paper.
}

peroxidation and haemolysis [2]. Further experiments demonstrated that ROS are also responsible for a significant depletion of the pyridine coenzyme pool mainly because of ATP consumption due to the activity of reducing enzymes [3]. Both processes are responsible for a reduction of the energy charge (i.e., ATP and GTP concentrations) of most normal cells and for an increase of ADP cellular concentration. NAD/NADH ratio as well is raised due to the increased energy consumption while adenosine monophosphate (AMP) deaminase, one of the main targets of oxidative stress [3], seems to depress energy metabolism by blocking the rescue pathway of purine nucleotides.

Several types of cells, including erythrocytes, contain different defense mechanisms against free radical-induced lipid peroxidation, which include both enzymatic (such as 
catalase, superoxide dismutase and glutathione peroxidase) and non-enzymatic factors (e.g., reduced glutathione and other prominent representatives of dietary antioxidants, such as ascorbate (vitamin C), tocopherols (vitamin E), carotenoids, selenium and flavonoids). All these molecules have been shown to react with free radicals reducing reactive species-mediated damages both in vitro and in vivo [3]. Intracellular antioxidant species may act in vivo to decrease oxidative damage to DNA, protein and lipids, thus reducing the risk of systemic diseases complications and cancer $[4,5]$.

Flavonoids are a large group of polyphenolic antioxidants that occur in several fruits, vegetables, and beverages such as tea and wine. Similarly, many plants contain a range of potential and powerful antioxidants. The biological, pharmacological and medical properties of polyphenols, have been also extensively reviewed [6,7].

Recently, a standard aqueous stem bark extract from selected species of Mangifera indica L. (Anacardiaceae), which has been used in pharmaceutical formulations in Cuba under the brand name of Vimang ${ }^{\circledR}$, has been reported to show a potent in vivo and in vitro anti-inflammatory activity [8,9], immunomodulation on rat macrophages [10] and a strong in vitro and in vivo antioxidant effect $[11,12]$.

Different studies demonstrated that mango stem bark extract could be useful to prevent the hyperproduction of reactive oxygen species (ROS) by peritoneal macrophages and from (TPA)-induced oxidative damage in serum, liver, and brain of mice, being more active than vitamin $\mathrm{C}$, vitamin $\mathrm{E}$, and $\beta$ carotene [12]. This extract also shows a very powerful scavenger activity for hydroxyl radicals $\left(\mathrm{OH}^{\prime}\right)$ and hypochlorous acid, associated to a relevant inhibitory effect on the peroxidation of rat brain phospholipids and a protective effect against DNA damage induced by iron/bleomycin or copperphenantroline models [11].

The chemical composition of Vimang ${ }^{\circledR}$ has been characterized by chromatographic (planar, liquid and gas) methods, mass spectrometry and UV/Vis spectrophotometry [13]. The total polyphenol content of Vimang ${ }^{\circledR}$ determined by the FolinCiocalteu method and expressed as gallic acid equivalents, was $34 \mathrm{~g} / 100 \mathrm{~g}$ dry weight. Chemical studies have enabled the isolation and identification of phenolic acids, phenolic esters, flavan-3-ols, mangiferin, which is the predominant component of this extract [13], and micronutrients as selenium [14].

The mangiferin content was determined by HPLC methods and found to represent about $13 \%$ of the powdered extract, i.e., about $50 \%$ of polyphenols with antioxidant activity present in crude mango extract. Mangiferin has been previously tested in vitro for its antioxidant [15-17], immuno-stimulating and antiviral properties [18] and it was found (i) to protect hepatocytes, lymphocytes, neutrophils and macrophages from oxidative stress $[19,20]$, (ii) to reduce atherogenicity in streptozotocin diabetic rats [21] and (iii) to reduce the streptozotocin-induced oxidative damage to cardiac and renal tissues in rats [22].

On the whole, these data prompted us to analyze the efficacy of this molecule, as well as of the crude mango extract Vimang ${ }^{\circledR}$ against oxidative damage to erythrocytes. Along this line, this study was designed to determine the effect of Vimang and mangiferin, the main polyphenols present in mango extracts, on the MDA release in erythrocytes as well as on the energy metabolism after hydrogen peroxide exposure ex vitro on red blood cells from healthy individuals. EGCG [23] was used as a reference compound in order to compare the activity of Vimang and mangiferin.

\section{Materials and methods}

\subsection{Plant Material}

M. indica was collected from a cultivated field located in the region of Pinar del Rio, Cuba. Voucher specimens of the plant (Code: 41722) were deposited at the Herbarium of Academy of Sciences, guarded by the Institute of Ecology and Systematic from Ministry of Science, Technology, and Environmental, Havana, Cuba. Stem bark extract of $M$. indica was prepared by decoction and concentrated by evaporation and spray dried to obtain a fine brown powder, which was used as the standardized active ingredient of $\operatorname{Vimang}^{\circledR}$ formulations. It melts at $210-215{ }^{\circ} \mathrm{C}$ with decomposition.

The extract contains a defined and standardized mixture of components such as polyphenols, terpenoids, steroids, fatty acids and microelements [14] and it was provided by the Center of Pharmaceutical Chemistry, Havana, Cuba. A phytochemical investigation of mango stem bark extract has led to the isolation of seven phenolic constituents (namely gallic acid, 3,4-dihydroxy benzoic acid, gallic acid methyl ester, gallic acid propyl ester, mangiferin, $(+)-$ catechin, (-) epicatechin, benzoic acid and benzoic acid propyl ester, with mangiferin as the main polyphenol present). Mangiferin content was determined by HPLC methods [13] and it represents approximately $13 \%$ of powdered extract.

Mangiferin was purified from a $5 \mathrm{mg} / \mathrm{mL}$ solution of the lyophilized powder mentioned above. It was extracted with methanol $(85 \%)$ and crystallized in aqueous ethylacetate as described in [24]. Further analysis demonstrated that mangiferin purity was about $95 \%$ by high performance liquid chromatographic (HPLC) analysis using PDA detector $(254 \mathrm{~nm})$ and a mobile phase of acetonitrile and 3\% acetic acid (16:84) [22].

Purified EGCG was purchased from Sigma Chemical.

\subsection{Induction of oxidative stress to human erythrocytes}

The simplicity, availability and ease of isolation make erythrocytes an excellent model for membrane studies and redox analysis [25]. Free radical damage to erythrocytes was performed as described previously [26]. In brief, peripheral venous blood samples were obtained from healthy volunteers and collected into heparinized tubes. After $10 \mathrm{~min}$ centrifugation at $1853 \times \mathrm{g}$ and $4{ }^{\circ} \mathrm{C}$, carried out within $15 \mathrm{~min}$ of withdrawal, erythrocytes were washed twice with a large volume of $10 \mathrm{mM}$ glucose supplemented PBS. After the second wash, packed erythrocytes were gently resuspended with PBS-glucose to obtain a $5 \%$ haematocrit and preincubated at $37^{\circ} \mathrm{C}$ for $10 \mathrm{~min}$ in the presence of $1 \mathrm{mM} \mathrm{NaN}_{3}$ (to inhibit catalase activity). Subsequently, they were divided into various aliquots of $1.6 \mathrm{~mL}$ for each experimental treatment. All of these, except the controls tubes, were challenged with different concentrations of $\mathrm{H}_{2} \mathrm{O}_{2}(1,2,5$ and $10 \mathrm{mM}$ ) with or without the addition of different concentrations of the natural extract Vimang $(0.1,10,50$ and $100 \mu \mathrm{g} / \mathrm{mL})$, its main component, mangiferin (1, 10 and $100 \mu \mathrm{g} / \mathrm{mL})$ and EGCG $(0.01,0.1,1$ and $10 \mu \mathrm{M})$ as reference compound. After $60 \mathrm{~min}$ at $37^{\circ} \mathrm{C}$, cells were kept for $60 \mathrm{~s}$ in an ice bath and then centrifuged at $1853 \times \mathrm{g}$ for $10 \mathrm{~min}$ at $4{ }^{\circ} \mathrm{C}$. Supernatants were divided into two parts: one was used for determining haemoglobin concentration, the other was deproteinized using $70 \% \mathrm{HClO}_{4}(10: 1, \mathrm{v} / \mathrm{v})$ to measure the concentration of metabolites released in the incubation medium. Preliminary experiments demonstrated that in our conditions the highest non-haemolytic $\mathrm{H}_{2} \mathrm{O}_{2}$ concentration was $10 \mathrm{mM}$. Packed erythrocytes were deproteinized by adding ice-cold $1.2 \mathrm{M} \mathrm{HClO}_{4}$ $(1: 2, w / w)$. Both deproteinized red blood cells and supernatants were centrifuged at $20,690 \times \mathrm{g}$ for $10 \mathrm{~min}$ at $4{ }^{\circ} \mathrm{C}$, neutralized by adding $5 \mathrm{M}$ $\mathrm{K}_{2} \mathrm{CO}_{3}$ in ice, filtered through a $0.45 \mu \mathrm{M}$ Millipore-HV filter and then analyzed 
by HPLC $(100 \mu \mathrm{L})$ for the simultaneous direct determination of malondialdehyde (MDA) and adenine nucleotides [27].

\subsection{Biochemical analysis}

Concentrations of MDA and high-energy phosphates were determined on $100 \mu \mathrm{L}$ of perchloric acid extract by an ion-pairing HPLC method [27] using a Vydac $250 \times 4.6 \mathrm{~mm}, 5-\mu \mathrm{m}$ particle size column, with its own guard column (Eka Chemicals AB, Bohus, Sweden), and using tetrabutylammonium hydroxide as the pairing reagent. Briefly, separation of different metabolites was obtained by forming a step gradient (adapted to the column length increase with respect to the original method [27]) with two buffers of the following composition: buffer A, $10 \mathrm{mM}$ tetrabutylammonium hydroxide, $10 \mathrm{mM}$ $\mathrm{KH}_{2} \mathrm{PO}_{4}, 0.25 \%$ methanol $\mathrm{pH} 7.00$; buffer $\mathrm{B}, 2.8 \mathrm{mM}$ tetrabutylammonium hydroxide, $100 \mathrm{mM} \mathrm{KH}_{2} \mathrm{PO}_{4}, 30 \%$ methanol $\mathrm{pH} 5.50$. The gradient was: $10 \mathrm{~min}$ $100 \%$ buffer A; 3 min $90 \%$ buffer A; 10 min 70\% buffer A; 12 min 55\% buffer A; $15 \min 45 \%$ buffer $A ; 10 \min 25 \%$ buffer $A ; 5$ min $0 \%$ buffer $A$. The flow rate throughout chromatographic runs was $1.2 \mathrm{~mL} / \mathrm{min}$ and the column temperature was kept at a constant $23{ }^{\circ} \mathrm{C}$ by using water-jacketed glassware. The HPLC apparatus consisted of a Surveyor LC Pump (ThermoFinnigan Italia, Rodano, Milan, Italy) connected to a Surveyor PDA Detector (ThermoFinnigan Italia) at 200-300 nm. Acquisition and analysis of data were performed using the ChromQuest program (ThermoQuest Italy). Comparison of areas, retention times and absorbance spectra of the peaks of sample chromatograms with those of freshly prepared ultrapure standards allowed the calculation of the concentration of the various compounds at $267 \mathrm{~nm}$ (the maximum of MDA absorbance spectrum) and the identification of the different metabolites. Haemoglobin and percentage haemolysis were calculated by standard haematological techniques [28] using a Jasco-685 double beam spectrophotometer.

Energy charge potential (ECP) was calculated according to [29] by means of the following relationship:

$\mathrm{ECP}=\mathrm{ATP}+0.5 \mathrm{ADP} / \Sigma \mathrm{NT}$

where $\Sigma \mathrm{NT}(=\mathrm{ATP}+\mathrm{ADP}+\mathrm{AMP})$ is the sum of adenine nucleotides.

\subsection{Statistical analysis}

Data were entered into the GraphPad Prism statistical analysis program (GraphPad, San Diego). Comparison of results from various incubations conditions were done by one-way analysis of variance (ANOVA). Analysis $a$ posteriori was carried out using Dunnett's, Bonferroni's or Tukey's tests whenever significant effects of different molecules were found on MDA production. In particular, unequal sample size correction, if necessary, was always applied to Dunnett's test; Bonferroni's test was used for multiple comparison and Tukey's test was used to analyze media and standard deviations in different experiments.

\section{Results}

\subsection{Analysis of metabolic decay}

In order to study the effects of antioxidants on oxidative stress, we analyzed both metabolic decay and lipid peroxidation in human erythrocytes. A preliminary paper [27] demonstrated that with a simple ion-pairing HPLC analysis, it is possible to simultaneously detect the amount of adenine nucleotide derivatives and malondialdehyde so as to obtain information about energy metabolism and the peroxidative damage. A typical elution pattern of PCA extract from erythrocytes is shown in Fig. 1, where the assignment of peaks to the corresponding compounds has been performed by comparing the retention times of the samples with respect to those obtained with a standard mixture. On the basis of the results obtained, we compared the effects of different concentrations of mangiferin, Vimang extract and EGCG on energy charge of red blood cells.

Fig. 2 shows that the main phosphorylated compounds necessary for all the energy requiring reactions of erythrocyte

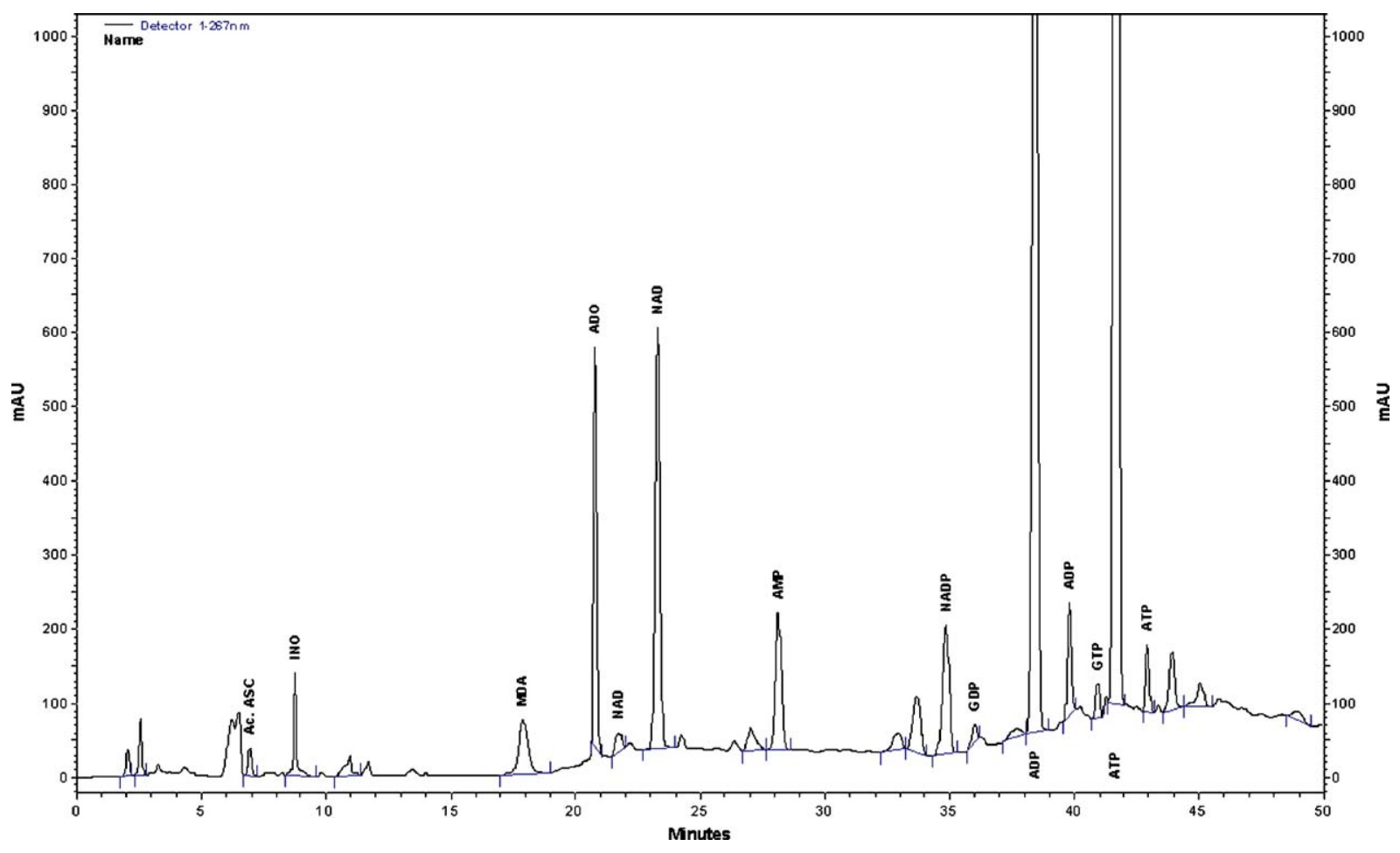

Fig. 1. A typical chromatogram obtained by using ion-pairing HPLC column as described in Materials and methods. Results are referred to $20 \mu \mathrm{L}$ of PCA extract of control RBC. 


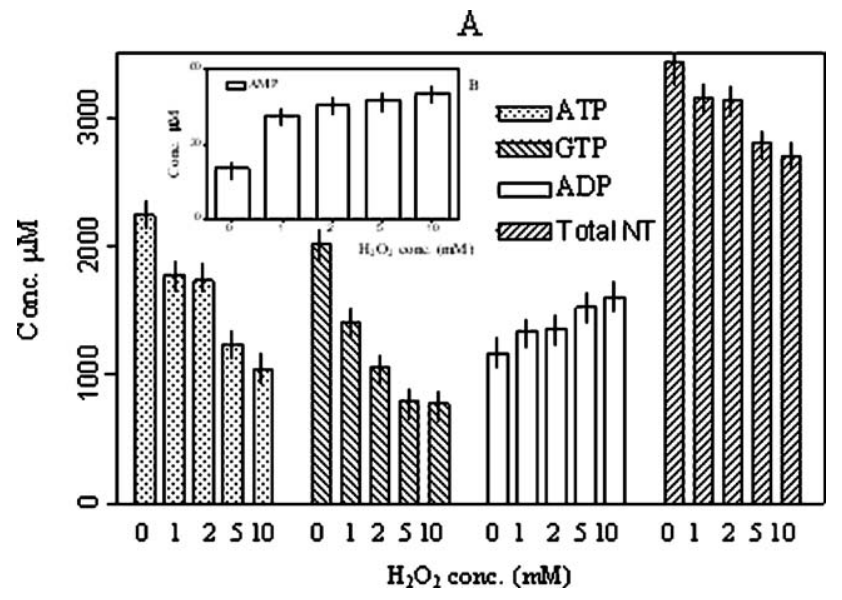

Fig. 2. Effects of $\mathrm{H}_{2} \mathrm{O}_{2}$ on ATP, GTP, ADP, total nucleotides (Total NT) and AMP concentrations. Data reported are referred to results obtained in a typical experiment performed in triplicate. Standard error never exceeded $5 \%$ of the value of each column. Different concentrations of $\mathrm{H}_{2} \mathrm{O}_{2}$ are reported in the abscissa. Differences in ATP, GTP ADP and total NT concentrations were significant $(P<0,05)$ between 0 and $10 \mathrm{mM} \mathrm{H}_{2} \mathrm{O}_{2}$ concentrations.

metabolism, i.e., ATP and GTP, were significantly reduced after $\mathrm{H}_{2} \mathrm{O}_{2}$ challenge in a dose-dependent manner, whereas usually a dose-dependent decrease of total nucleotidic pool was observed upon $\mathrm{H}_{2} \mathrm{O}_{2}$ addition $(3438 \mu \mathrm{M}$ in controls vs. $2700 \mu \mathrm{M}$ in $10 \mathrm{mM} \mathrm{H}_{2} \mathrm{O}_{2}$ treated $\mathrm{RBC}$ ). The oxidative stress activates one major route of pyridine nucleotide catabolism (i.e., protein ADP-ribosylation) without acute inhibitory effect on the other one (i.e., cleavage by NAD glycohydrolase) [30]. The increase of NAD observed in our conditions, ranging from $580 \mu \mathrm{M}$ in untreated cells to $934 \mu \mathrm{M}$ in $10 \mathrm{mM} \mathrm{H}_{2} \mathrm{O}_{2}$-treated cells (data not shown) further supports the occurrence of an overproduction of oxygen radicals observed upon $\mathrm{H}_{2} \mathrm{O}_{2}$ addition.

The energy potential charge, which in erythrocytes and other cells is roughly close to unit $(0,823$ in our experiments) decreases in a dose-dependent manner when $\mathrm{H}_{2} \mathrm{O}_{2}$ is added, falling to 0.684 when $\mathrm{H}_{2} \mathrm{O}_{2}$ concentration is $10 \mathrm{mM}$ (Fig. 3).

\subsection{Protective effects of Vimang, mangiferin and EGCG on energy charge potential}

The treatment of erythrocytes with increasing concentrations of Vimang $(0.10-100 \mu \mathrm{g} / \mathrm{mL})$, mangiferin $(1-100 \mu \mathrm{g} / \mathrm{mL})$ and EGCG $(0.01-10 \mu \mathrm{M})$ was significantly effective in inhibiting the depletion of high energy phosphates. In particular, over a concentrations range between 0.1 and $100 \mu \mathrm{g} / \mathrm{mL}$, Vimang restores, in a dose-dependent way, the ATP, GTP an total NT content of RBC, thus confirming its anti oxidant activity (Fig. 4, panel A). This protective activity on total NT concentration also mirrors that on NAD and ADP production, induced by ROS (Fig. 4, panel B). Energy potential charge was also preserved in a dose-dependent way by Vimang addition, further confirming the antioxidant activity of the mixture (Fig. 4, panel C).

Similar results have been obtained by using mangiferin. Results shown in Fig. 5 (panel A) demonstrate the antioxidant activity of this compound measured both as ATP, GTP and total NT savings associated to a decrease of NAD and ADP content (Fig. 5, panel B), which had been increased after $\mathrm{H}_{2} \mathrm{O}_{2}$ addition. Energy charge potential, decreased in $\mathrm{H}_{2} \mathrm{O}_{2}$-treated $\mathrm{RBC}$, was also restored after addition of mangiferin in a dosedependent way.

EGCG, a well-known antioxidant compound, was evaluated for its protective activity on nucleotidic pool and energy charge potential. Results demonstrate that this molecule is highly active and is able to significantly reduce, even at low concentrations, the oxidative stress induced by $\mathrm{H}_{2} \mathrm{O}_{2}$ on nucleotides (Fig. 6, panel A), on ADP and NAD production (Fig. 6, panel B) and on energy charge potential (Fig. 6, panel C).

On the whole, both total NT concentration and ECP, modified after $\mathrm{H}_{2} \mathrm{O}_{2}$ addition, were restored in a dosedependent way by all compounds used, thus confirming the protective effects of the molecules used in our study.

\subsection{Analysis of MDA production}

Preliminary experiments demonstrated that MDA production followed a time-dependent increase after $\mathrm{H}_{2} \mathrm{O}_{2}$ addition in a dose-dependent way (data not shown).

The effect of Vimang and its main component, mangiferin, on lipid peroxidation in RBC is shown in Fig. 7. Total concentration of MDA (i.e., intracellular+extracellular) increased after addition of $10 \mathrm{mM} \mathrm{H}_{2} \mathrm{O}_{2}$ from non detectable levels in the control samples to approximately $250 \mu \mathrm{M}$. Vimang was very effective in reducing erythrocytes membrane lipoperoxidation; thus, even at a concentration as low as $0.1 \mu \mathrm{g} / \mathrm{mL}$ it was capable of bringing about a more than 2-fold decrease of MDA concentration. Similar results have been obtained by using mangiferin and EGCG.

\subsection{Activity of Vimang, mangiferin and EGCG on haemolysis in presence of $\mathrm{H}_{2} \mathrm{O}_{2}$}

MDA can decrease red blood cells fluidity. The lowered membrane fluidity compromises erythrocyte deformability

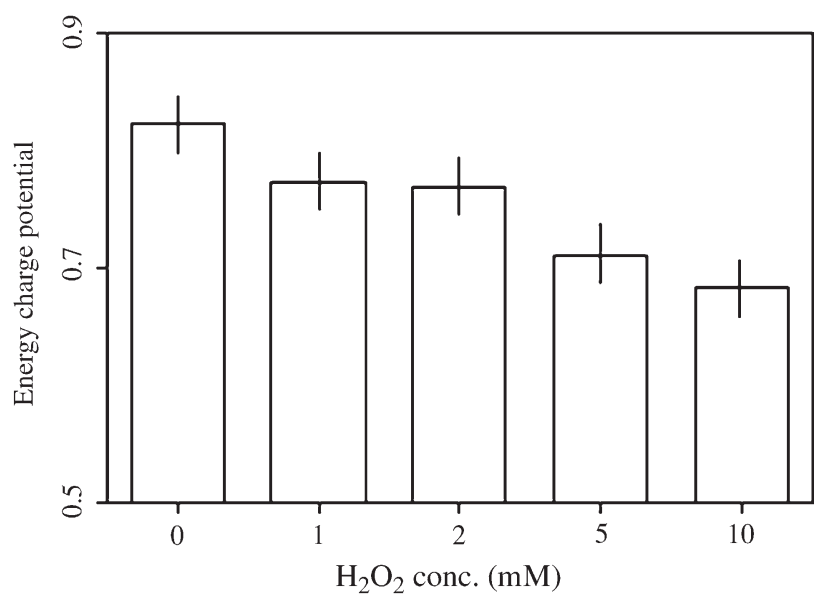

Fig. 3. Effects of different concentrations of $\mathrm{H}_{2} \mathrm{O}_{2}$ on energy charge potential. Energy charge is referred as Energy charge $=\mathrm{ATP}+1 / 2 \mathrm{ADP} / \mathrm{ATP}+\mathrm{ADP}+\mathrm{AMP}$. Differences in energy charge was significant $(P<0,05)$ between 0 and $10 \mathrm{mM}$ $\mathrm{H}_{2} \mathrm{O}_{2}$ concentrations. 

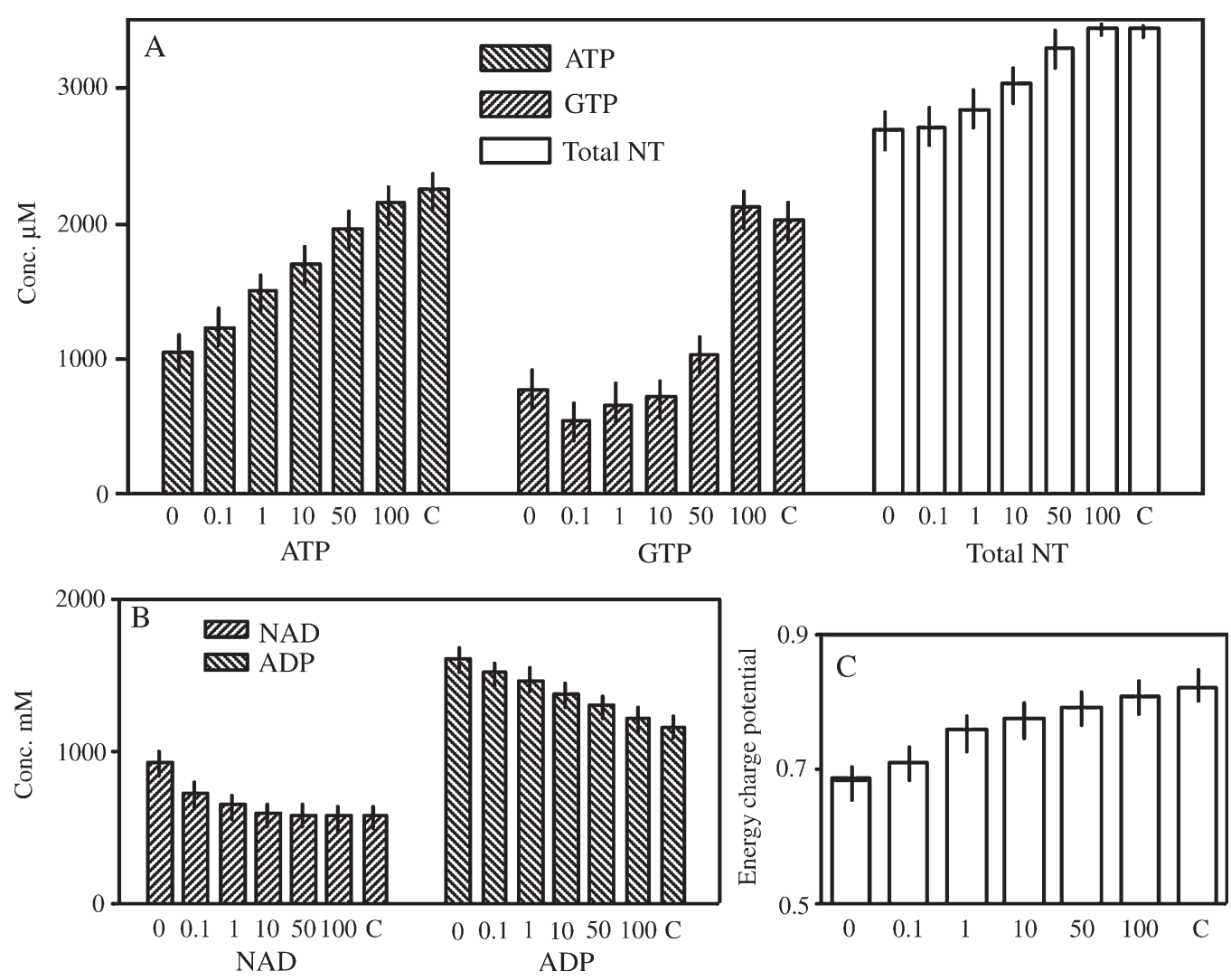

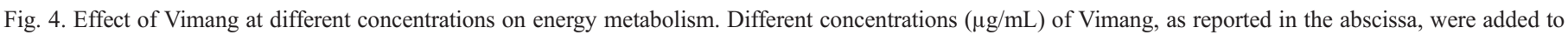

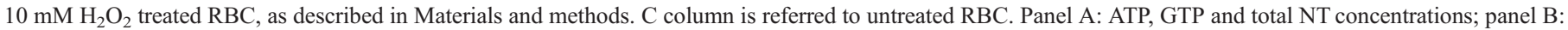

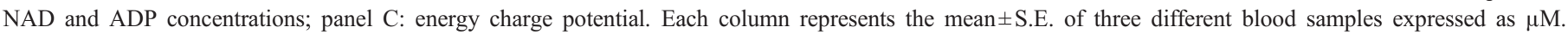

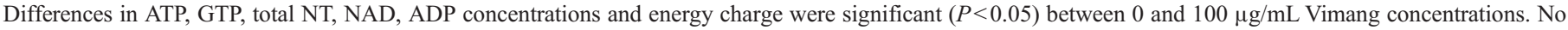
statistically significant difference between $100 \mu \mathrm{g} / \mathrm{mL}$ Vimang and control RBC has been observed.

which in turn disturbs oxygen delivery to the tissues and enhances haemolysis which could be a marker of oxidative stress. In our conditions we observed a dose-dependent increase on haemoglobin release in $\mathrm{H}_{2} \mathrm{O}_{2}$-treated erythrocytes. The amount of haemolysis was reduced in a dose-dependent manner in the presence of the different test substances used in our study, thus further confirming their activity on lipid peroxidation and membrane fluidity (Fig. 8). In particular, a reduction of haemolysis by about $50 \%$ was observed when Vimang was used at a concentration of $100 \mu \mathrm{g} / \mathrm{mL}$. Even higher haemolysis reduction has been observed when EGCG was used.

\subsection{Effects of Vimang, mangiferin and EGCG on ascorbate production}

Ascorbate is a natural antioxidant able to reduce the activity of free radicals. Since ascorbate is involved in vitamin E redox cycling and vitamin $\mathrm{E}$ is the main membrane-bound lipid peroxidation chain breaker, a decrease in ascorbate concentration might be responsible for an enhanced MDA production. Ascorbate amount rapidly decreases in the presence of $\mathrm{H}_{2} \mathrm{O}_{2}$, thus favouring lipid peroxidation. The concentration of ascorbate as a sensitive intracellular antioxidant [31] was checked and it turns out that Vimang, mangiferin and EGCG markedly enhance, in a dose-dependent way, the production of
RBC-mediated ascorbate, which had been decreased upon $\mathrm{H}_{2} \mathrm{O}_{2}$ addition; these data further confirm the protective effects that these molecules can exert on erythrocytes (Fig. 9). In particular, addition of $100 \mu \mathrm{g} / \mathrm{mL}$ Vimang or mangiferin and $10 \mathrm{mM}$ EGCG fully restores ascorbate production after $\mathrm{H}_{2} \mathrm{O}_{2}$ induced oxidative stress.

\section{Discussion}

The aim of the present work was to prove the phytotherapeutical significance of an officinal and popular medicinal extract and its main ingredient, on the basis of their antioxidant activity due to their influence on pathological free radical reactions. Experimental methods were planned and developed in order to measure the antioxidant, free radical scavenging and membrane protecting activities and to monitor the capacity of these natural compounds to reduce the extend of lipid peroxidation. Some previous "in vivo" experiments demonstrated that Vimang is a better scavenger of ROS and a more efficient inhibitor of oxidation tissue damage than vitamin $C$, vitamin E, $\beta$-carotene and mangiferin [12]. Mangiferin, constituting approximately $10 \%$ of the whole Vimang extract [13], was also identified as a ROS scavenger.

Different models have been proposed to detect both the effects of reactive oxidizing species and the activity of natural 

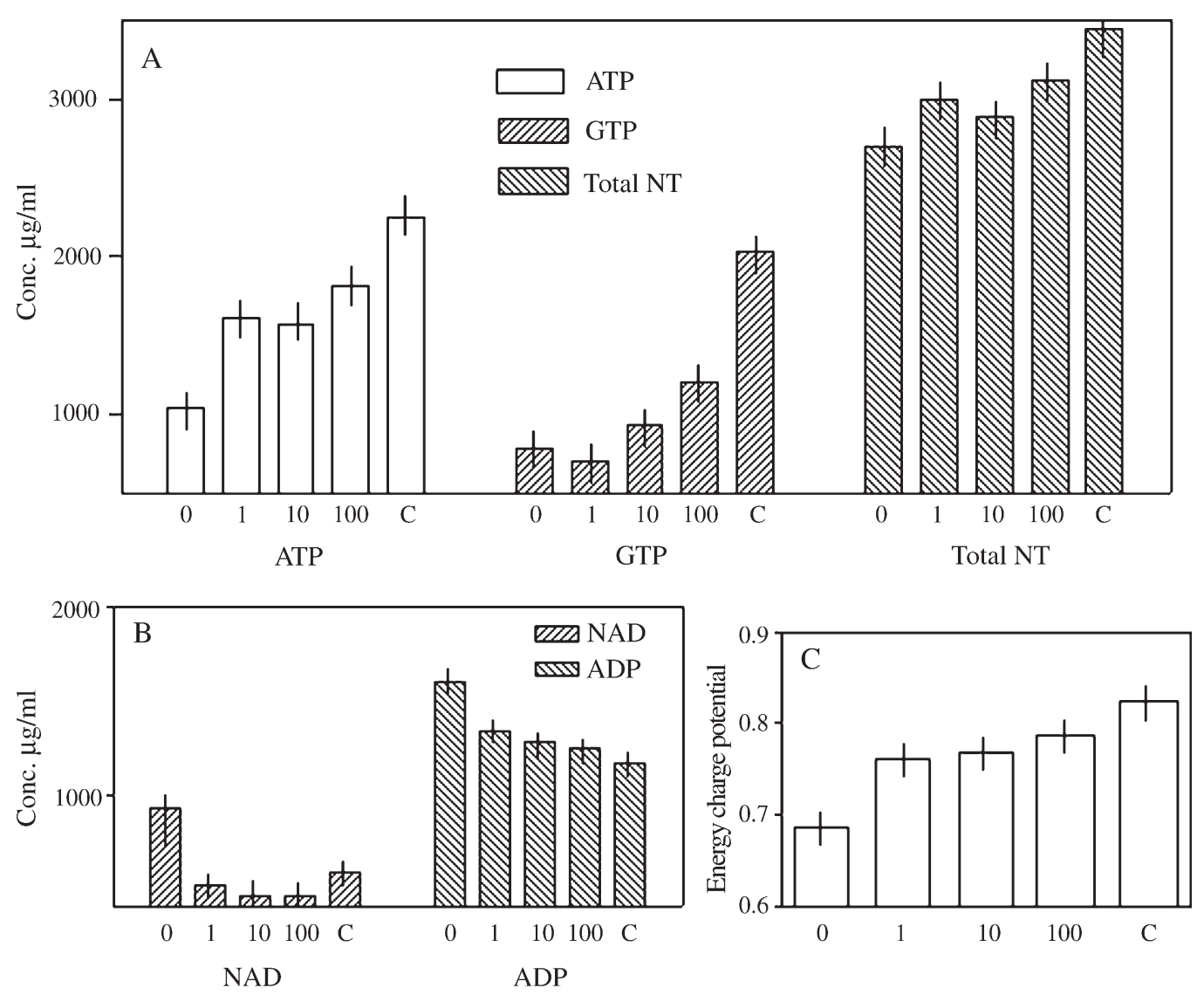

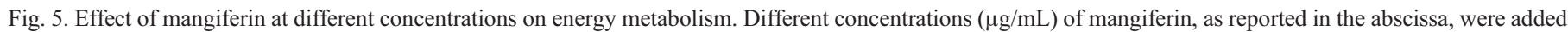

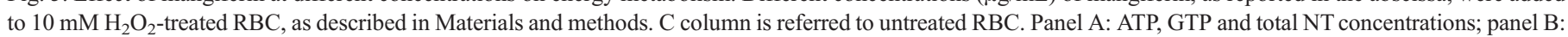

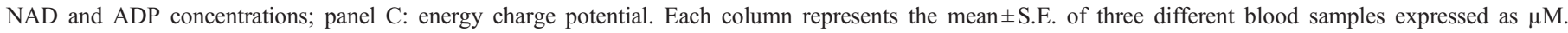

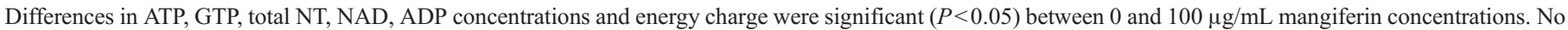
statistically significant difference between $100 \mu \mathrm{g} / \mathrm{mL}$ mangiferin and control RBC has been observed.

and synthetic scavengers; among them, erythrocytes rapidly became a useful general model to evaluate the effects of ROS and antioxidants on a very accurate cellular system. Besides the practical implications of this cell system, there is a physiological interest because erythrocytes represent an important component of the antioxidant capacity of blood, comprising the glutathione system and intracellular enzymes, such as superoxide dismutase and catalase. ATP and energy substrate concentrations in the cell are not random; they are part of stress response of the cell and an abrupt rise in energy demand, due to the increased ROS concentration, induces the adenylate pool to respond first by a decrease in its size. As a consequence of the imbalance between phosphorylating and dephosphorylating processes in the presence of oxidants, such as $\mathrm{H}_{2} \mathrm{O}_{2}$, both total NT and ECP were also remarkably reduced in a dose-dependent manner. In our conditions, after $1 \mathrm{~h}$ incubation at $37^{\circ} \mathrm{C}$ in the presence of the highest $\mathrm{H}_{2} \mathrm{O}_{2}$ concentration $(10 \mathrm{mM})$, about $46 \%$ ATP depletion was observed with a concomitant significant ADP increase (37\%). AMP concentration rose from $20.45 \mu \mathrm{M}$ to $50.1 \mu \mathrm{M}$ and GTP concentration decreased from $2.025 \mathrm{mM}$ in control to $781 \mu \mathrm{M}$ when $10 \mathrm{mM} \mathrm{H}_{2} \mathrm{O}_{2}$ was used to trigger oxidative stress. Adenosine, a marker of ATP degradation, also increased during $\mathrm{H}_{2} \mathrm{O}_{2}$ incubation, in a dose-dependent manner, from $320 \mu \mathrm{M}$ for control erythrocytes to $1.36 \mathrm{mM}$ when $\mathrm{H}_{2} \mathrm{O}_{2}$ was used at a concentration of $10 \mathrm{mM}$.

On the whole, these observations could be explained by the tetravalent reduction of the reactive oxygen species (produced by $\mathrm{H}_{2} \mathrm{O}_{2}$ ) which, in turn, consumes ATP, thus progressively reducing the energy charge. The rapid decrease in ATP content is further associated to a loss of ability for a correct reduction of oxygen catalysis. This phenomenon, in combination with the oxidation of hypoxanthine to xanthine and uric acid catalyzed by xanthine oxidase, has been proposed as one of the main intracellular sources of superoxide anions. Although not particularly toxic, this molecule may be transformed, through different mechanisms, into various highly reactive and toxic oxygen radicals, such as the strong oxidant hydroxyl radical $\mathrm{OH}$. Therefore, antioxidants which are able to impair the formation of oxygen reactive species could block ATP consumption, thus maintaining in a dose-dependent way the energy charge $\approx 1.0$.

At all concentrations used, Vimang, its main component mangiferin and EGCG have been shown to be able to scavenge ROS, thus inhibiting all those processes leading to $\mathrm{RBC}$ damage, energy charge decrease and membrane destabilization. In particular, all molecules used restore, in a dose-dependent way, the ATP, GTP and total NT content of RBC, thus 

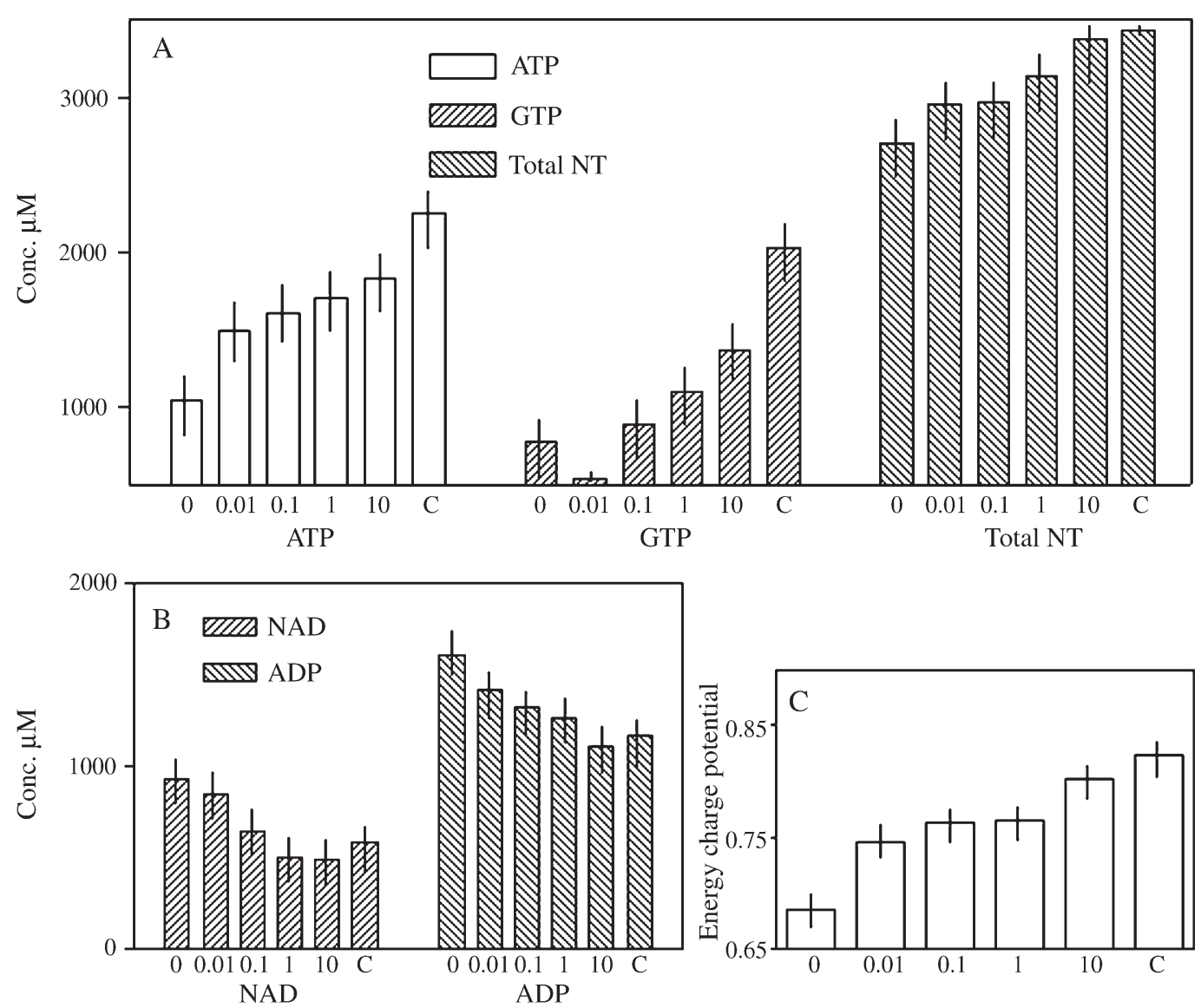

Fig. 6. Effect of EGCG at different concentrations on energy metabolism. Different concentrations $(\mu \mathrm{g} / \mathrm{mL})$ of EGCG, as reported in the abscissa, were added to $10 \mathrm{mM} \mathrm{H}_{2} \mathrm{O}_{2}$ treated $\mathrm{RBC}$, as described in Materials and methods. C column is referred to untreated RBC. Panel A: ATP, GTP and total NT concentrations; panel B: NAD and ADP concentrations; panel C: energy charge potential. Each column represents the mean \pm S.E. of three different blood samples expressed as $\mu$ M. Differences in ATP, GTP, total NT, NAD, ADP concentrations and energy charge were significant $(P<0.05)$ between 0 and $10 \mu \mathrm{g} / \mathrm{mL}$ EGCG concentrations. No statistically significant difference between $10 \mu \mathrm{g} / \mathrm{mL}$ EGCG and control RBC has been observed.

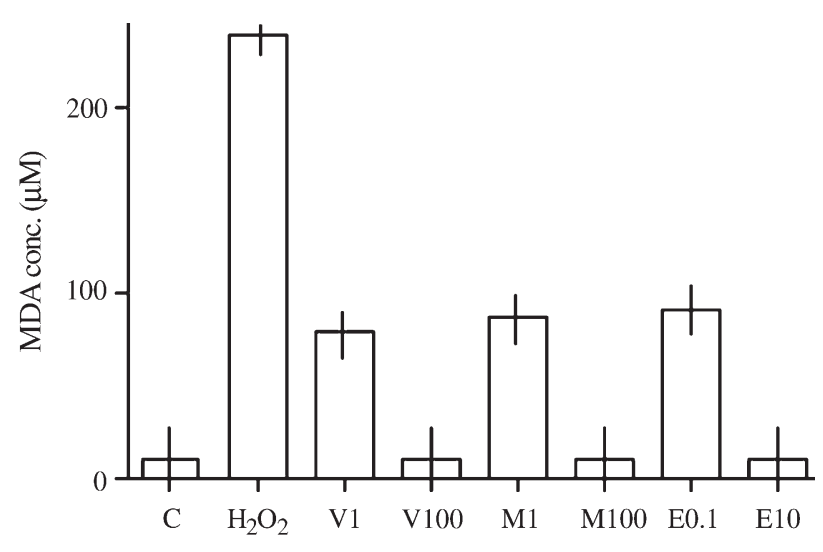

Fig. 7. Effect of different compounds on MDA production. C: untreated RBC; $\mathrm{H}_{2} \mathrm{O}_{2}: 10 \mathrm{mM} \mathrm{H} \mathrm{H}_{2} \mathrm{O}_{2}$-treated RBC; V1: $\mathrm{H}_{2} \mathrm{O}_{2}$-treated $\mathrm{RBC}$ incubated with $1 \mu \mathrm{g} / \mathrm{mL}$ Vimang; V100: $\mathrm{H}_{2} \mathrm{O}_{2}$-treated RBC incubated with $100 \mu \mathrm{g} / \mathrm{mL}$ Vimang; M1: $\mathrm{H}_{2} \mathrm{O}_{2}$-treated $\mathrm{RBC}$ incubated with $1 \mu \mathrm{g} / \mathrm{mL}$ mangiferin; $\mathrm{M} 100: \mathrm{H}_{2} \mathrm{O}_{2^{-}}$ treated RBC incubated with $100 \mu \mathrm{g} / \mathrm{mL}$ mangiferin; E0.1: $\mathrm{H}_{2} \mathrm{O}_{2}$-treated $\mathrm{RBC}$ incubated with $0.1 \mu \mathrm{M}$ EGCG; E10: $\mathrm{H}_{2} \mathrm{O}_{2}$-treated RBC incubated with $10 \mu \mathrm{M}$ EGCG. Each column represents the mean \pm S.E. of three different blood samples expressed as $\mu$ M. Differences between V1 vs. V100, M1 vs. M100 and E0,1 vs. E10 were significant $(P<0.05)$.

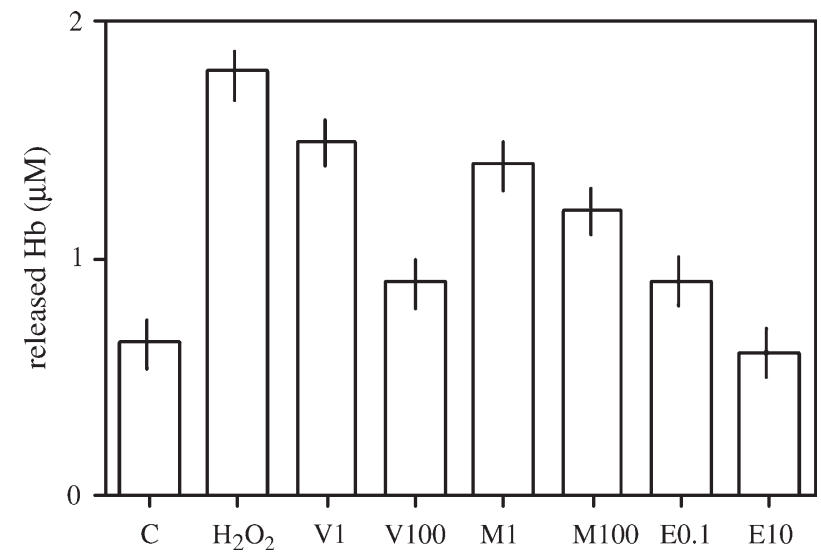

Fig. 8. Effect of different compounds on $\mathrm{H}_{2} \mathrm{O}_{2}$-induced $\mathrm{RBC}$ haemolysis. C: untreated RBC; $\mathrm{H}_{2} \mathrm{O}_{2}: 10 \mathrm{mM} \mathrm{H} \mathrm{H}_{2} \mathrm{O}_{2}$-treated RBC; V1: $\mathrm{H}_{2} \mathrm{O}_{2}$-treated $\mathrm{RBC}$ incubated with $1 \mu \mathrm{g} / \mathrm{mL}$ Vimang; V100: $\mathrm{H}_{2} \mathrm{O}_{2}$-treated RBC incubated with $100 \mu \mathrm{g} / \mathrm{mL}$ Vimang; M1: $\mathrm{H}_{2} \mathrm{O}_{2}$-treated $\mathrm{RBC}$ incubated with $1 \mu \mathrm{g} / \mathrm{mL}$ mangiferin; $\mathrm{M} 100$ : $\mathrm{H}_{2} \mathrm{O}_{2}$-treated $\mathrm{RBC}$ incubated with $100 \mu \mathrm{g} / \mathrm{mL}$ mangiferin; E0.1: $\mathrm{H}_{2} \mathrm{O}_{2}$-treated RBC incubated with $0.1 \mu \mathrm{M}$ EGCG; E10: $\mathrm{H}_{2} \mathrm{O}_{2}$-treated $\mathrm{RBC}$ incubated with $10 \mu \mathrm{M}$ EGCG. Each column represents the mean \pm S.E. of three different blood samples expressed as $\mu \mathrm{M}$. Differences between V1 vs. $\mathrm{V} 100$ and $\mathrm{E} 0,1$ vs. E10 were significant $(P<0.05)$. 


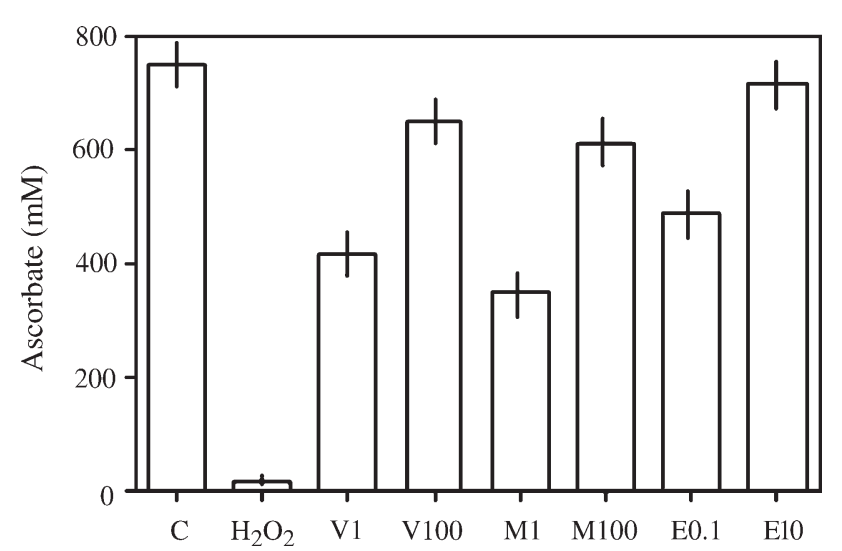

Fig. 9. Effect of different compounds on ascorbate production in $\mathrm{H}_{2} \mathrm{O}_{2}$-treated RBC. C: untreated RBC; $\mathrm{H}_{2} \mathrm{O}_{2}: 10 \mathrm{mM} \mathrm{H}_{2} \mathrm{O}_{2}$-treated RBC; V1: $\mathrm{H}_{2} \mathrm{O}_{2}$-treated RBC incubated with $1 \mu \mathrm{g} / \mathrm{mL}$ Vimang; V100: $\mathrm{H}_{2} \mathrm{O}_{2}$ treated $\mathrm{RBC}$ incubated with $100 \mu \mathrm{g} / \mathrm{mL}$ Vimang; $\mathrm{M} 1: \mathrm{H}_{2} \mathrm{O}_{2}$-treated $\mathrm{RBC}$ incubated with $1 \mu \mathrm{g} / \mathrm{mL}$ mangiferin; M100: $\mathrm{H}_{2} \mathrm{O}_{2}$-treated $\mathrm{RBC}$ incubated with $100 \mu \mathrm{g} / \mathrm{mL}$ mangiferin; E0.1: $\mathrm{H}_{2} \mathrm{O}_{2}$-treated RBC incubated with $0.1 \mu \mathrm{M}$ EGCG; E10: $\mathrm{H}_{2} \mathrm{O}_{2}$-treated $\mathrm{RBC}$ incubated with $10 \mu \mathrm{M}$ EGCG. Each column represents the mean \pm S.E. of three different blood samples expressed as $\mu \mathrm{M}$. Differences between V1 vs. V100, M1 vs. M100 and E0,1 vs. E10 were significant $(P<0.05)$. All treatment resulted in a significant increase $(P<0.05)$ of ascorbate concentrations vs. $\mathrm{H}_{2} \mathrm{O}_{2}$ treated RBC.

confirming their anti-oxidant activity (Figs. 4-6). This protective activity on total NT concentration mirrors also the NAD and ADP production, induced by ROS. Energy potential charge was also preserved in a dose-dependent way, further confirming the antioxidant activity of the mixture (Fig. 4, panel C). Scavenging activity of the molecules used in the study was further confirmed by membrane stabilization, clearly indicating that ROS can damage RBC membrane by acting on membrane phospholipids. Addition of Vimang, mangiferin and EGCG significantly reduces this damage, thus restoring membrane fluidity and stability. It must be pointed out that green tea polyphenol epigallocatechin gallate (EGCG) has been proposed as a cancer chemopreventive and several studies have shown that EGCG can act as an antioxidant by trapping peroxyl radicals and inhibiting lipid peroxidation. This compound blocks lipid peroxidation in erythrocyte membranes induced by t-butylhydroperoxide and it protected ATPases against t-BHPinduced damage [23]. This paper describes, for the first time, the protective activity of this molecule on nucleotides pool and energy charge, thus confirming its strong antioxidant and scavenger activity on a very sensitive system such as RBC challenged with $\mathrm{H}_{2} \mathrm{O}_{2}$.

Erythrocytes and erythrocyte membrane have a high ratio of polyunsaturated fatty acids to total lipids, indicating susceptibility to lipid peroxidation; moreover, RBC are highly vulnerable to lipid peroxidation due to constant exposure to high oxygen tension and the presence of high $\mathrm{Fe}$ ion concentrations [32]. Extensive investigations demonstrated the key role of oxidative stress and iron release in a reactive form causing membrane protein damage via the Fenton reaction and hydroxyl radical production. In the absence of an efficient protection by antioxidant factors (such as flavonoids), oxidative stress is responsible for iron release in reactive form, bringing about red cells haemolysis [33]. A study performed using a spectrophotometric titration technique [34] revealed that tea polyphenols (TPP) were capable of binding ferric ion in a stoichiometric amount to form a redox inactive Fe-TPP complex. Quantitative analysis suggests that one or more major catechins from the TPP preparations are the likely iron binding compounds accounting for the antioxidant effects of TPP on red blood cells. Recent investigations have demonstrated that Vimang is able to prevent iron mediated mitochondrial damage by means of oxidation of reduced transition metals required for the production of superoxide and hydroxyl radicals and direct free radical scavenging activity. This study describes the iron-complexing ability of Vimang as the primary mechanism for protection of rat liver mitochondria against $\mathrm{Fe}^{2+}$-citrate-induced lipoperoxidation; on the other hand, mangiferin could form a complex with $\mathrm{Fe}^{2+}$, accelerating the $\mathrm{Fe}^{2+}$ oxidation and the formation of more stable $\mathrm{Fe}^{+}$-polyphenol complexes, which are unable to participate in Fenton-type reactions, and the lipoperoxidation propagation phase [35].

Dietary antioxidants are believed to protect humans from disease and aging, since they play a major role in maintaining the homeostasis of the oxidative balance. Indeed, a large number of previous studies has also reported enhanced protection by polyphenols on RBC [36]. Plant-derived phenols are reported to have a broad spectrum of free-radical scavenging, antioxidant and protective activities [37-41]. In other studies red wine polyphenols, containing $3.5 \mathrm{mM}$ gallic acid equivalent (GAE) of phenolic compounds, prevented oxidative modifications on the RBC system, such as haemolysis and lipid peroxidation. The protective effect was less apparent when red blood cells were incubated with wines containing lower levels of polyphenols [42]. (-)Epicatechin has been shown to enhance antioxidative defense systems in diabetic erythrocytes [43].

We should underline that mangiferin constitutes approximately $10 \%$ of the whole extract and, considering this, it might be possible that the efficacy of Vimang at $100 \mu \mathrm{g} / \mathrm{mL}$ could be similar to that obtained for the pure mangiferin at $10 \mu \mathrm{g} / \mathrm{mL}$. EGCG, in our experimental model, was found to be more active than mangiferin, thus indicating the importance and the possible synergistic effects due to other polyphenols in the extract.

By-products of lipid peroxidation are low-molecular weight compounds, such as carbohydrates (ethane and pentane) and aldehydes, e.g., MDA, which is the by-product of both peroxidation of phospholipids and the activation of the arachidonate cycle. Therefore, it is generally regarded as a marker of peroxidative damage induced in cell membranes by both physical and chemical oxidative stresses, rendering its determination in biological samples particularly interesting [44]. Although the inhibitory activity of Vimang and mangiferin on MDA production has been described previously $[11,12]$, its determination in the present work by HPLC technique furnishes more reliability and reproducibility to the obtained results. Nevertheless, these products where studied for the first time in a new context, erythrocytes system, giving another explanation of 
the beneficial effects of Vimang consumption by patients suffering of oxidative stress.

Vitamin $\mathrm{C}$ is considered to be one of the most powerful, least toxic natural antioxidants. It is found in high concentrations in many tissues; human plasma contains about $60 \mathrm{mM}$ ascorbate [31]. After interaction with ROS, ascorbate is oxidized to dehydro-ascorbate via the intermediate ascorbyl free radical. Dehydro-ascorbate is recycled back to ascorbic acid by the enzyme dehydro-ascorbate reductase. Thus, dehydro-ascorbate is found at only very low levels as compared to ascorbate. As a scavenger of ROS, ascorbate has been shown to be effective against $\mathrm{H}_{2} \mathrm{O}_{2}$, the hydroxyl radical, the superoxide radical anion, singlet oxygen and in aqueous solutions it also scavenges reactive nitrogen oxide species efficiently, preventing the nitration of target molecules. We also determined the ascorbic acid concentration in the analyzed samples as an attempt to elucidate the mechanisms of the antioxidant action of the extract. The enhancement of this molecule in peroxidized cells treated with the extract might indicate the activation of antioxidant defenses by all molecules used in the study. Since Vimang has been studied in different in vitro and in vivo systems, where it elicited a clear antioxidant effect, its action in human beings might be predictable. A sign of this has been a clinical trial where Vimang supplementation on HIV patients shows evidence of improved antioxidant status and reduced oxidative damage [45].

The results presented herein, allow us to conclude that besides of the aforementioned antioxidant effects of Vimang, mangiferin and EGCG, they exert an important role in the protection of erythrocytes from ROS production, contributing to the integrity and functionality of these cells. Their protective activities against erythrocyte damage constitutes another reason to consider them as a promising therapeutic agents for a great number of pathologies where cell oxidative stress is implicated.

\section{Acknowledgment}

A la memoria de Janet Rodríguez, investigadora que murió inesperadamente el 3 de diciembre del 2005 con solo 28 años, cuando todavía este trabajo no había sido publicado. Janet simboliza el talento, la sencillez y la belleza de una joven cubana excepcional, querida por todos sus colegas y amigos, permanecerá por siempre en el corazón y la memoria de quienes tuvimos el inmenso placer de conocerla y compartir con ella su virtuosismo y apasionada dedicación al trabajo científico.

\section{References}

[1] B. Halliwell, J.M.C. Gutteridge, Free radicals in biology and medicineVol nr 135 (1985) 136.

[2] J. Stocks, T.L. Dormandy, The auto-oxidation of human red cell lipids induced byhydrogen peroxide, Br. J. Hematol. 20 (1971) 95-111.

[3] B. Tavazzi, D. Di Pierro, A.M. Amorini, G. Fazzina, M. Tuttobene, B. Giardina, G. Lazzarino, Energy metabolism and lipid peroxidation of human erythrocytes as a function of increased oxidative stress, Eur. J. Biochem. 267 (2000) 684-689.

[4] D. Anderson, B.J. Phillips, Comparative in vitro and in vivo effects of antioxidants, Food Chem. Toxicol. 37 (9-10) (1999) 1015-1025.
[5] C. Costagliela, T. Libondi, M. Menzione, E. Rimandi, G. Auricchio, Vitamin E and red blood cell glutathione, Metabolism 34 (1985) 712-714.

[6] C.A. Rice-Evans, N.J. Miller, G. Paganda, Structure-antioxidant activity relationship of flavonoids and phenolic acids, Free Radical Biol. Med. 20 (1996) 933-956.

[7] S.V. Jovanovic, S. Steenken, M. Tosic, B. Marjanovic, M.G. Simic, Flavonoids as antioxidants, J. Am. Chem. Soc. 116 (1994) 4846-4851.

[8] G. Garrido, D. González, C. Delporte, N. Backhouse, G. Quintero, A.J. Núñez-Sellés, M. Morales, Analgesic and anti-inflammatory effects of Mangifera indica L. extract (Vimang), Phytother. Res. 15 (2001) 18-21.

[9] R. Delgado, G. Garrido, D. González, B. Herrera, A. Beltrán, Mangifera indica L. extract (VIMANG) as a natural antioxidant with antinociceptive and anti-inflammatory properties, Minerva Medica 92 (2001) 98-102.

[10] D. Garcia, R. Delgado, F.M. Ubeira, J. Leiro, Modulation of rat macrophage function by the Mangifera indica L. extracts Vimang and mangiferin, Int. Immunopharmacol. 2 (2002) 797-806.

[11] G. Martínez, R. Delgado, G. Pérez, G. Garrido, A.J. Núñez-Sellés, O.S. León, Evaluation of the in vitro antioxidant activity of Mangifera indica L. extract (Vimang), Phytother. Res. 14 (2000) 424-427.

[12] G.M. Sánchez, L. Re, A. Giuliani, A.J. Núñez-Sellés, G.P. Davison, O.S. León-Fernández, Protective effects of Mangifera indica L. extract, mangiferin and selected antioxidants against TPA-induced biomolecules oxidation and peritoneal macrophage activation in mice, Pharmacol. Res. 42 (2000) 565-573.

[13] A.J. Núñez-Sellés, H. Vélez-Castro, J. Agüero-Agüero, J. GonzálezGonzález, F. Naddeo, F. De Simone, L. Rastrelli, Isolation and quantitative analysis of phenolic constituents, free sugars, fatty acids and polyols from mango (Mangifera indica L.) stem bark aqueous decoction used in Cuba as nutritional supplement, J. Agric. Food Chem. 50 (2000) 762-766.

[14] Center of Pharmaceutical Chemistry, Pharmaceutical compositions including a mixture of polyphenols, terpenoids, steroids, fatty acids, and microelements with antioxidant, analgesic, anti-inflammatory, and antispasmodic properties. Patent 203/98, OCPI-Havana, Cuba (2002).

[15] B. Markus, Electrochemical behaviour and antioxidant activity of some natural polyphenols, Helv. Chim. Acta 79 (1996) 1147-1158.

[16] L.F. Rouillard, A.J. Thiais, J.R. Robin, Cosmetic or pharmaceutical composition containing, as active ingredient, mangiferine or its derivatives, in pure or in plant extracts. US Patent 5, 824 (1998) 320.

[17] T. Sato, A. Kawamoto, A. Tamura, Y. Tatsumi, T. Fujii, Mechanism of antioxidant action of pueraria glycoside (PG)-1 (an isoflavonoid) and mangiferin (a xanthonoid), Chem. Pharm. Bull. 40 (3) (1992) 721-724.

[18] M.S. Zheng, Z.Y. Lu, Antiviral effect of mangiferin and isomangiferin on Herpes simplex Virus, Chin. Med. J. 103 (1990) 160-165.

[19] D. Remirez, S. Tafazoli, R. Delgado, A.A. Harandi, P.J. O'Brien, Preventing hepatocyte oxidative stress cytotoxicity with Mangifera indica L. extract (Vimang), Drug Metab. Drug Interact. 21 (1) (2005) 19-29.

[20] S. Muruganandan, J. Lal, P.K. Gupta, Immunotherapeutic effects of mangiferin mediated by the inhibition of oxidative stress to activated lymphocytes, neutrophils and macrophages, Toxicology 215 (1-2) (2005 Nov 5) 57-68.

[21] S. Muruganandan, K. Srinivasan, S. Gupta, P.K. Gupta, J. Lal, Effect of mangiferin on hyperglycemia and atherogenicity in streptozotocin diabetic rats, J. Ethnopharmacol. 97 (3) (2005 Mar 21) 497-501.

[22] S. Muruganandan, S. Gupta, M. Kataria, J. Lal, P.K. Gupta, Mangiferin protects the streptozotocin-induced oxidative damage to cardiac and renal tissues in rats, Toxicology 176 (3) (2002 Jul. 15) 165-173.

[23] Y. Saffari, S.M. Sadrzadeh, Green tea metabolite EGCG protects membranes against oxidative damage in vitro, Life Sci. 74 (12) (2004) $1513-1518$.

[24] S. Muruganandan, J. Lal, P.K. Gupta, Immunotherapeutic effects of mangiferin mediated by the inhibition of oxidative stress to activated lymphocytes, neutrophils and macrophages, Toxicology 215 (1-2) (2005) $57-68$.

[25] G.M. Wagner, B.H. Lubin, D.T. Ye Chiu, Oxidative damage to red cells, in: C.K. Chow (Ed.), Cellular Antioxidant Defense Mechanisms, CRC Press, Boca Raton, 1988, pp. 185-195.

[26] B. Tavazzi, D. Di Pierro, A.M. Amorini, G. Fazzina, M. Tuttobene, B. Giardina, G. Lazzarino, Energy metabolism and lipid peroxidation of 
human erythrocytes as a function of increased oxidative stress, Eur. J. Biochem. 267 (3) (2000) 684-689.

[27] G. Lazzarino, D. Di Pierro, B. Tavazzi, L. Cerroni, B. Giardina, Simultaneous separation of malondialdehyde, ascorbic acid and adenite nucleotide derivatives from biological samples by ion pairing highperformance liquid chromatography, Anal. Biochem. 197 (1991) 191-196.

[28] M. Miki, H. Tamai, M. Mino, Y. Yamamoto, E. Niki, Free-radical chain oxidation on rat red blood cells by molecular oxygen and its inhibition by alfa-tocopherol, Arch. Biochem. Biophys. 258 (1987) 373-380.

[29] D.E. Atkinson, The energy charge of the adenylate pool as a regulatory parameter. Interaction with feedback modifiers, Biochemistry 7 (11) (1968) 4030-4034.

[30] D.R. Janero, D. Hreniuk, H.M. Sharif, K.C. Prout, Hydroperoxide-induced oxidative stress alters pyridine nucleotide metabolism in neonatal heart muscle cells, Am. J. Physiol. 264 (1993) 1401-1410.

[31] S. Mendiratta, Z. Qu, J.M. May, Erythrocytes defenses against hydrogen peroxide: the role of ascorbic acid, Biochim. Biophys. Acta 1380 (3) (1998) 389-395.

[32] W. Pawlak, J. Kedziora, K. Zolynski, K. Kedziora-Kornatowska, J. Blaszczyk, P. Witkowski, J. Zieleniewski, Effect of long term bed rest in men on enzymatic antioxidative defense and lipid peroxidation in erythrocytes, J. Gravit. Physiol. 5 (1) (1998) 163-164.

[33] S.K. Jain, N. Mohandas, M.R. Clark, S.B. Shobel, The effect of MDA, a product of lipid peroxidation on the deformability, dehydration and $51 \mathrm{Cr}$ survival of erythrocytes, Br. J. Haematol. 53 (1983) 247-252.

[34] L.N. Grinberg, H. Newmark, N. Kitrossky, E. Rahamim, M. Chevion, E.A. Rachmilewitz, Protective effects of tea polyphenols against oxidative damage to red blood cells, Biochem. Pharmacol. 54 (9) (1997) 973-978.

[35] G. Pardo-Andreu, R. Delgado, J. Velho, N.M. Inada, C. Curti, A.E. Vercesi, Mangifera indica L. extract (Vimang) inhibits Fe2+-citrateinduced lipoperoxidation in isolated rat liver mitochondria, Pharmacol. Res. 51 (5) (2005) 427-435.
[36] K.A. Youdim, B. Shukitt-Hale, S. MacKinnon, W. Kalt, J.A. Joseph, Polyphenolics enhance red blood cell resistance to oxidative stress: in vitro and in vivo, Biochim. Biophys. Acta 1523 (1) (2000) 117-122.

[37] R.W. Owen, A. Giacosa, W.E. Hull, R. Haubner, G. Wurtele, B. Spiegelhalder, H. Bartsch, Olive-oil consumption and health: the possible role of antioxidants, Lancet Oncol. 1 (2000) 107-112.

[38] C. Manna, P. Galletti, V. Cucciolla, G. Montedoro, V. Zappia, Olive oil hydroxytyrosol protects human erythrocytes against oxidative damages, J. Nutr. Biochem. 10 (3) (1999) 159-165.

[39] M.A. Abou-Seif, A. Rabia, M. Nasr, Antioxidant status, erythrocyte membrane lipid peroxidation and osmotic fragility in malignant lymphoma patients, Clin. Chem. Lab. Med. 38 (2000) 737-742.

[40] A. Maneva, B. Taleva, L. Maneva, Lactoferrin-protector against oxidative stress and regulator of glycolysis in human erythrocytes, Z. Naturforsch. 58 (3-4) (2003) 256-262.

[41] M. Sivonova, I. Waczulikova, E. Kilanczyk, M. Hrnciarova, M. Bryszewska, B. Klajnert, Z. Durackova, The effect of pycnogenol on the erythrocyte membrane fluidity, Gen. Physiol. Biophys. 23 (1) (2004) 39-51.

[42] I.I. Tedesco, M. Russo, P. Russo, G. Iacomino, G.L. Russo, A. Carraturo, C. Faruolo, L. Moio, R. Palumbo, Antioxidant effect of red wine polyphenols on red blood cells, J. Nutr. Biochem. 11 (2) (2000) 114-119.

[43] S.I. Rizvi, M.A. Zaid, Intracellular reduced glutathione content in normal and type 2 diabetic erythrocytes: effect of insulin and (-)epicatechin, J. Physiol. Pharmacol. 52 (3) (2001) 483-488.

[44] D. Di Pierro, B. Tavazzi, G. Lazzarino, B. Giardina, Malondialdehyde is a biochemical marker of peroxidative damage in the isolated reperfused rat heart, Mol. Cell. Biochem. 116 (1992) 193-196.

[45] L. Gil, G. Martínez, I.G. Blanco, A. Tarinas, A. Alvarez, R. Molina, M. Robaina, R. Tápanes, J.P. Ávila, M. Guevara, A.J. Núñez-Sellés, O.S. León, Effects of Vimang on oxidative stress and marker of disease progression in HIV/AIDS patients, Free Radical Res. 36 (I) (2002) $107-109$. 